\title{
Talking at Cross Purposes Negotiation of the sick role with a MUS patient as a real time social process
}

\section{Christel Tarber, Lisbeth Frostholm \& Emma Rehfeld}

\section{Linguistics, Aarhus University}

christel_tarber@hotmail.com

The Research Clinic for Functional Disorders and Psychosomatics lisbfros@rm.dk

The Research Clinic for Functional Disorders and Psychosomatics emmarehf@rm.dk

Tarbel, Christel, Frostholm, Lisbeth \& Rehfeld, Emma. (2016). 'Talking at cross purposes: negotiation of the sick role with a MUS patient as a realt time social process, Tidsskrift for Forskning i Sygdom og Samfund, nr. 24, 61-88

Medically unexplained symptoms (MUS) challenge our perception of illness. As a consequence, a MUS-patient's legitimised entry into the sick role, as defined by Parsons, poses a problem for physicians and patients alike. The encounter between patients with MUS and physicians therefore can be frustrating for both parties. The present study is a single case analysis of such an encounter in primary care. Using the microanalytical method of conversation analysis, this study aims to provide a contextualised description of both the patient's and the physician's different orientations to the purpose of the encounter. This approach locates the source of the frustration in the participants' incompatible interactional projects. The patient is oriented towards the emotional and life world aspects of her situation. She is pursuing recognition, not only of the destructive effect that the symptoms have on all aspects of her life, but also of herself as a morally sound person. The physician, on the contrary, is oriented towards avoiding to psychologise the patient and keeping the focus on reaching an agreement about future clinical action. The physician uses ancillary questions to refocus the emotionally loaded contributions from the patient and maintain structured progression. Consequently, physician 
and patient are talking at cross purposes, and it is argued that this is a structurally facilitated pitfall of the conventional format of primary care visits that physicians are trained to adhere to.

\section{Background}

Medically unexplained symptoms (MUS) is one of several terms used for »[c]onditions where the patient complains of physical symptoms that cause excessive worry or discomfort or lead the patient to seek treatment but for which no adequate organ pathology or pathophysiological basis can be found." (Fink et al 2002, p. 99). Patients with MUS are often experienced as complex and difficult to treat by the general practitioner (GP). Descriptions such as "difficult" (Clements et al 1980), "heartsink" (O'Dowd 1988) or "frustrating" (Wileman et al 2002) reflect the GPs' experience of powerlessness (Wileman et al 2002; Salmon et al 2005), inability, and dissatisfaction (Hartz et al 2000; Reid et al 2001) when dealing with this group of patients. The patients on their side, as they have no clinical or physical evidence of their suffering to show, report the experience of being stigmatised in the health care system and socially: Their credibility is undermined, and as a consequence their moral standards are called into question (Ware 1992; Åsbring \& Närvänen 2002; Werner et al 2004). Negative clinical findings commonly invite the interpretation, also by physicians, that the symptoms are caused by some psychological disturbance (Reid et al 2001). Thus, equally important is the experience of delegitimation that comes from being "psychologised « by physicians unable to provide a biomedical explanation and therefore resorting to a simplistic dualistic model of illness (Ware 1992; Åsbring \& Närvänen 2002; Rosendal et al 2005; Burbaum et al 2010). In their encounters with health practitioners, as a consequence, patients report putting an effort into being perceived as credible, i.e. as mentally balanced, but somatically ill, by not appearing "too strong or too weak, too healthy or too sick, or too smart or disarranged" (Werner \& Malterud 2003, p. 1414). At the same time, many patients with MUS do not dismiss a psychological component to their symptoms (Peters et al 2009). Thus, MUS-patients have been found to want comparatively more "emotional support" than other patients (Salmon et al 2005) and furthermore to give clues for the physician to pursue a more psychosocial line of talk (Salmon et al 2004).

The physician, thus, has to walk a fine line in the interaction with the patient with MUS. In order to provide high quality care for these patients while at the same time gaining their confidence, the GP has to operate at the intersection of 
several opposing pressures. Observing the specialist consensus on optimal management of MUS, the GP has to avoid embarking on the "somatic path" of investigation and treatment ad infinitum and instead attempt to reframe and reattribute the patient's understanding of the symptoms (Goldberg et al 1989; Mayou 1991; Fink et al 2002). The pitfall of such reframing is the danger of adopting - or being heard by the patient to have adopted - a unidirectional mind-to-body-model of somatisation of the unexplained physical symptoms (Burton 2003). In sum, and at the risk of oversimplifying, the GP must take serious the medically unexplained symptoms without making use of the usual somatic interventions, and at the same time provide emotional support without psychologising.

\section{Theoretical prerequisites}

Pertinent to the above described difficulties of both patients and physicians in the encounter about MUS, is the problem of legitimacy, i.e. of being recognised as being legitimately ill. This problem was initially formulated by Parsons and crystallised in the now well-known concept of »the sick role« (1951). Taking his point of departure in a capitalist moral economy, Parsons perceived of illness as a dysfunctional disturbance in both a biological and a social sense - the latter because it prevents a person from contributing to the common good (Parsons 1951, p. 430). The sick role, however, is a provision to protect the sick individual in that it "enables conformity within the deviance of illness" (Varul 2010, p. 76) through a set of normative rights and corresponding obligations. Entering the sick role, an individual thus has the right to exemption from normal social duties, e.g. work, but at the same time must resist to take advantage of any "secondary gains", social, emotional and economic, to be had from the sick role. In order to be perceived as innocent on this account, the individual is obliged to not in any way see the sick role as desirable, but to seek technically competent help and cooperate with this help in order to re-enter one's normal role in society (Parsons 1951, p. 437). Providing legitimate entry into the sick role is the privilege of physicians, who have "a gatekeeper function that is justified with reference to the medical profession's ability to identify objective biological or pathological findings, that is, signs of disease" (Glenton 2003, p. 2244). The absence of pathological signs, as in the case of MUS and other, mainly subjectively experienced illness, therefore means that legitimised entry into the sick role poses a problem for physicians and patients alike, as documented in a number of the above quoted articles. Although Parsons' model was quickly dismissed as applying only to major, acute physical illness (see e.g. Szasz \& Hollender 1956; 
Gallagher 1976), more recent articles have restored its relevance also for chronic illnesses (Glenton 2003; Varul 2010) and for MUS (Mik-Meyer \& Obling 2012), first and foremost because the "moral economy" that pertains to health and illness in Western, capitalist societies is essentially unchanged since its conception.

In the present study the Parsonian concept of the sick role was also found to be highly applicable, as it was clearly traceable in the displayed orientations of the participants to the analysed interaction. The analyses presented below thus exemplify how the question of being legitimately ill and the obligations that this entails is a very real issue with implications for the way in which patients present their problem and themselves in the medical encounter.

Of central importance for the analyses presented below is furthermore the issue of empathic communication in health care communication. In this area of research the focus has traditionally been on the identification of patients' displays of or cues to emotion as opportunities for giving recognition, displaying understanding and facilitating talk about underlying worries, problems etc. (Branch \& Malik, 1993; Suchman et al 1997; Zimmerman et al 2011). Not only does empathically responding to patients' emotional experiences serve a basic humane function, but it has also been found to be beneficial for a range of medically relevant purposes, e.g. for enhancing illness coping (Zachariae et al 2003) and satisfaction (Uitterhove et al 2009) and for reducing anxiety (Butow et al 2002). Other, mainly conversation analytic, work has focused on the interactionally instrumental functions of responding empathically. Beach \& Dixson (2001), in the context of medical history taking, thus describe how formulations of understanding can work as a means to both invite, but also to avoid, further talk on emotionally loaded subjects. Ruusuvuori (2007) demonstrates how displays of affiliation by health professionals can serve as sequence-closing devices that return the talk to the health problem under consideration. This line of work points to an important and inbuilt tension in medical encounters, namely that of attending to the medical problem under consideration while at the same time attending to the emotional dimensions thereof. This tension, however, is not restricted to medical encounters, but is a tension that underlies all conversational activity which involves the telling of a trouble, as has been described by Jefferson \& Lee (1981). In the context of ordinary conversation among friends, Jefferson \& Lee (1981) observe how the proffering of advice in response to someone having told a trouble is often met with rejection by the teller of the trouble, whereas this is not the case in professional-client interaction, i.e. in »service encounters«. This is a consequence of the different sets of interactional roles that the telling of a trouble sets up for the participants, as these sets of roles 
are primarily, but not exclusively, tied to the context in which the troubles-telling activity unfolds. In ordinary conversation, a troubles-telling entails the roles of troubles-teller and troubles-recipient. As shown by Jefferson \& Lee, the incumbency of these roles entails respectively exposing the trouble and listening to the trouble in a way that first and foremost focuses on the "teller and his experiences" (1981, p. 411), and furthermore makes relevant a certain degree of emotional reciprocity (Jefferson \& Lee 1981) from the troubles-recipient. This contrasts with the roles and orientations tied to the service encounter, in which the relevant roles of the participants are »advice-seeker» and »advice-giver«. In this context, therefore, the common focus is on the problem and its properties, not on the emotional aspects of the problem. However, participants to a troubles-telling, be it in an everyday or institutional setting, may orient differently to the activity and as a consequence take on incongruent roles and thereby produce misalignment. The data analyses that are presented in this article will pay close attention to the concrete interactional features that can result in such a misalignment.

\section{Objective}

So far, the bulk of research on patients with MUS and their communication with physicians has taken the form of either qualitative interviews, or coding and subsequent quantification of utterances into categories with no regard for the local context in which they were produced and obtained their meaning. This single case analysis, however, adopts a contextually sensitive perspective on the verbal contributions by both participants with a focus on the interaction between them. By providing a series of close-up images of a complex and delicate communicative situation, this interactional perspective can nuance and enrich our understanding of the set of problems we know to be inherent in the encounter between the general practitioner and patients with MUS. 


\section{Method}

\section{Data}

The consultation analysed is one of a corpus of 197 video recordings of consultations between 10 Danish GPs, recorded from October 2009 to November 2010. The GPs filled out a short questionnaire immediately after each consultation, classifying the patients' health problems. The present patient was categorised by her GP as having medically unexplained symptoms, dominated by physical pain and discomfort. The video was subsequently examined by Emma Rehfeld who in her capacity as a specialist in patients with MUS corroborated this evaluation and furthermore pointed out that core features of the patient's illness situation, i.e. the mistrust of the health care system and co-morbid health anxiety (elaborated below), are common among patients with severe medically unexplained symptoms. These characteristics add to the complexity of the case.

\section{Ethics}

The project has been registered with the Danish Data Protection Agency. Written consent was obtained from the patient, and she was informed, orally and in writing, that she could withdraw her consent anytime. Names and other material that could identify the participating individuals have been anonymised in text and transcripts.

\section{Method of Analysis}

The interaction is approached using the methodology of conversation analysis (CA) (Sidnell 2010). An inherent part of the CA methodology involves the production of detailed transcripts of the interaction to be studied, including temporal (e.g. pauses, overlapping talk) and qualitative features (e.g. volume, pitch, speed etc.) of the talk (Jefferson 2004). For an outline of the CA transcription conventions see appendix. While seeing interaction as actions performed by the interactants through verbal and embodied resources, CA concerns itself with how the participants display their perception of the relevant features of the setting and of the participants themselves. This is manifested not only on the lexical, grammatical, and turn-constructional level, but also on the level of turn-taking and sequential 
organisation. The performing of an action is seen as done in a contextually sensitive manner, the detailed analysis of which will enhance our understanding of what is at stake for the participants then and there. Rather than isolating and quantifying individual turns at talk, CA is interested in the participant perspective that a micro level, contextually, and sequentially sensitive analysis can yield.

The insights resulting from the application of this method to the case in question are presented as a series of analyses of transcribed excerpts of selected parts of the consultation. All examples have been translated from Danish to English as accurately and close to the original as possible, while maintaining understandable English ${ }^{1}$. English glosses are rendered in bold types, with line numbers that correspond to the Danish ones, but are marked with "a".

\section{Analyses}

\section{Case History}

The patient $(\mathrm{P})$ is a 58-year old woman with a complex history of illness. $\mathrm{P}$ is accompanied by her husband (SP). The following overview of P's situation has been pieced together on the basis of the talk that occurs during the consultation under consideration. 24 years earlier, $\mathrm{P}$ was subject to a faulty operation in the back of her neck, during which a nerve root was destroyed. P has since then suffered from chronic pain and has been through several futile reoperations. In her mid-thirties she therefore had to retire. As a result, P intensely distrusts the health care system and its practitioners. $\mathrm{P}$, however, also experiences other very bothersome symptoms, among them what she refers to as "flushings". Flushing is symptomatic for a range of conditions, and furthermore a cardinal symptom of carcinoid tumour. When first mentioned to her former GP, this symptom occasioned a blood sample to be taken. The sample revealed raised levels of serotonin, also a potential symptom of cancer, and P was hospitalised acutely. Arriving at the hospital, P's trauma was revived and she felt unable to spend the night there. Disregarding the exhortations of both her husband and the physician she walked out. Approximately 10 years later, a similar incident takes place. $\mathrm{P}$, therefore, is caught in a paradoxical situation, on the one hand anxious about the possibility of a carcinoid tumour, and on the other hand too fearful of staying in a hospital long enough to have it investigated. Along with the flushings, P furthermore complains of stomach-aches 
and a devastating fatigue. Both are general symptoms, but are also interpreted by $\mathrm{P}$ and her husband to be indicative of a carcinoid tumour. Given that $\mathrm{P}$ has had these symptoms for the past 13 years, however, the GP has no doubt that carcinoid tumour is not the problem. For the GP, the purpose of the visit is to propose a thorough examination with an endocrinologist, whom GP has consulted prior to the consultation, in an attempt to definitively rule out the suspicion of cancer or other "hidden" diseases as a first step towards reattributing P's understanding of her symptoms.

\section{Presenting the Problem: Normal Person - Extreme Situation}

As pointed out by Goffman (1959) there is an inescapable relation between presenting a problem and presenting yourself. P's problem, the paradoxical situation in which she is stuck, is a challenge to her credibility: If she is seriously anxious about having a deadly cancer, why then, for all these years, has she not taken the necessary measures to have her symptoms diagnosed and possibly treated, however frightening the process of doing so may be? In a Parsonian perspective, $\mathrm{P}$ thus is perceivable as too willingly accepting the sick role in order to obtain its additional gains. Excerpt 1, in which P presents the problem, nicely illustrates this complexity. The analysis, however, will be restricted to dealing with two aspects: Firstly, the interactional work that $\mathrm{P}$ does to counter potential sceptical hearings of her problem, in other words her effort to be perceived as a morally sound and credible person, who does in fact fulfil the obligations of the sick role. Secondly, the analysis will address a recurrent feature of the interaction, namely the "ancillary questions" (Jefferson 1984) that the GP can be seen to pose throughout the interaction. Such questions have the potential to derail $\mathrm{P}$ from her present direction of talk, and furthermore are a way of avoiding to reciprocate the emotional content of an utterance (Heritage 2011). 


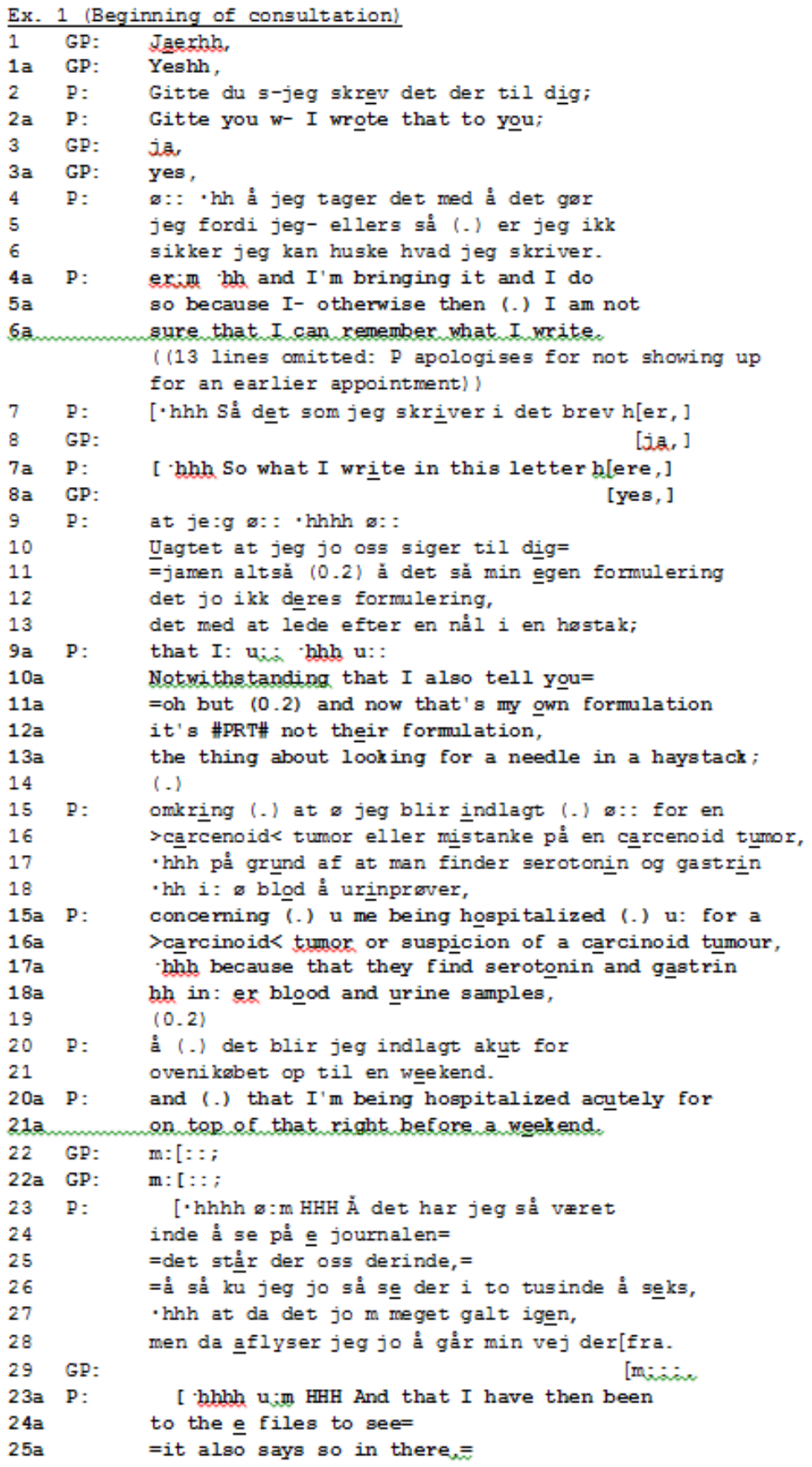




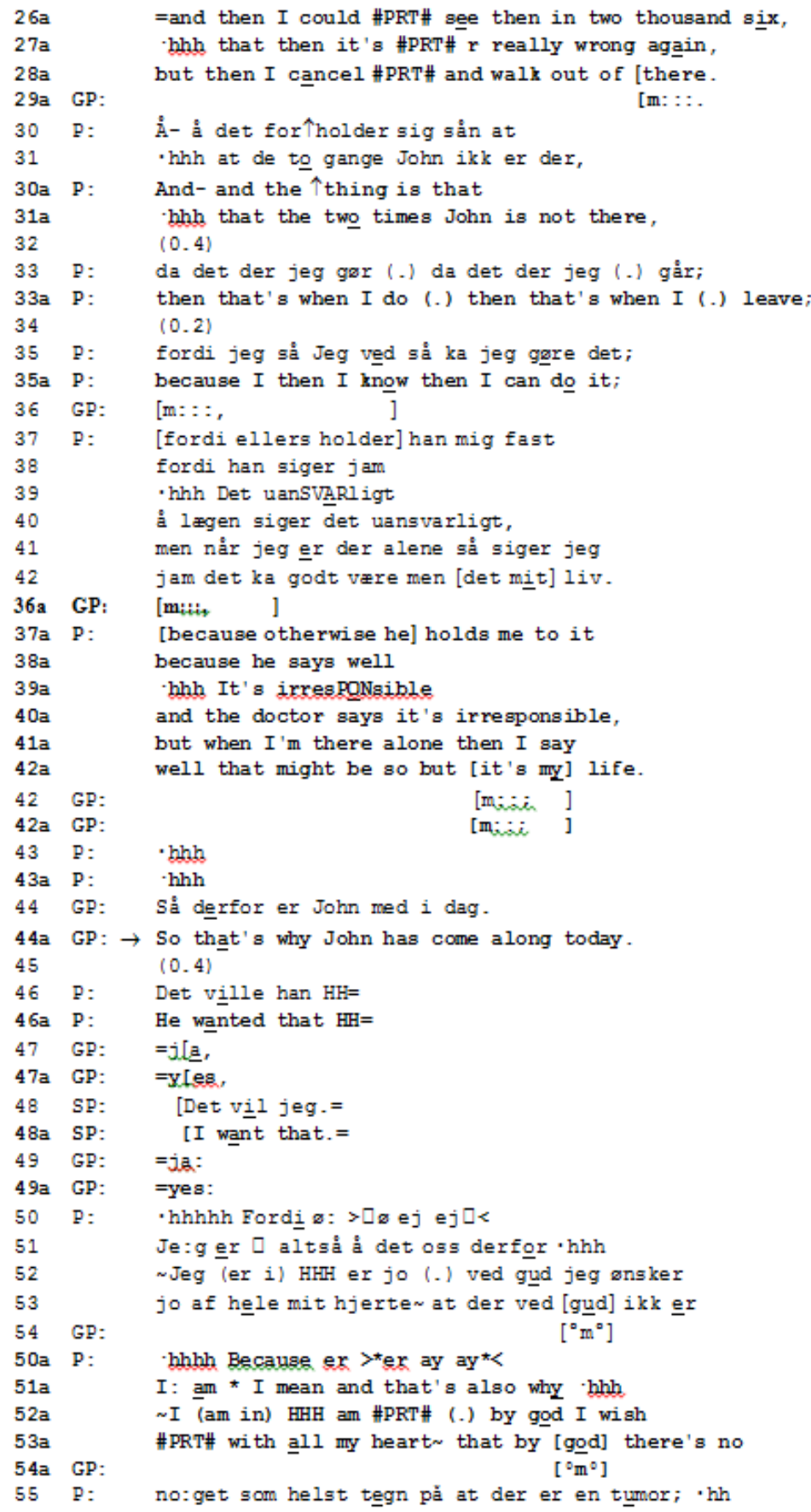




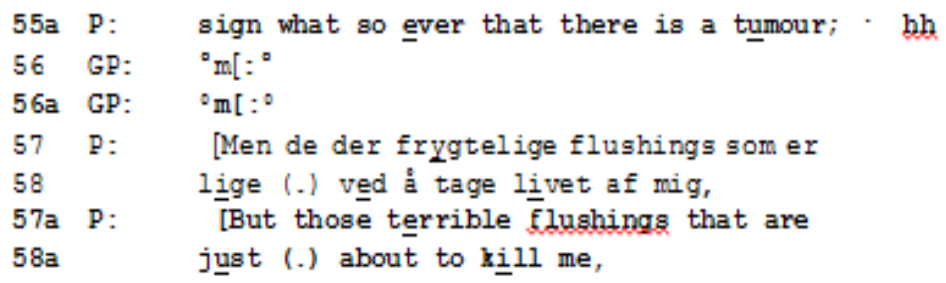

P on her own account begins the interaction by summing up her history of illness. In so doing, she is reading out loud from a piece of paper, originally written as a letter to the GP (line 2), explaining that she otherwise cannot remember (lines 4-6). The obvious implication of this is that P's condition is so severe as to cause memory problems. However, it simultaneously constructs her as a responsible person who is aware of her own problem and has taken measures to counter it.

$\mathrm{P}$ begins her problem presentation by accounting for not having shown up for a prior appointment with the GP because she was extremely tired that day. This passage has been omitted, not because it is irrelevant, but out of considerations for the focus and length of the data excerpt. P then initiates a story of an incident in the past of being acutely hospitalised for suspicion of cancer (lines 15-21). The reading out loud, maybe even citing from her own file (cf. lines 23-25), possibly explains P's use of medical terms like "serotonin" and "gastrin" and (lines 17), along with other quite formal words such as "notwithstanding" (line 10). These technical terms not only point to her previous experience with the health care system, but also to her being knowledgeable about the implication of these words. In lines 26-28 $\mathrm{P}$ reaches a central part of her problem, i.e. her history of hospital desertion. From the perspective of optimally managing a potential cancer, P's behaviour is hasardous and makes her appear careless and negligent of her own health. Her reported behaviour is morally accountable from a Parsonian perspective, and in lines 30-42, P delivers an account. This account, however, does not address the moral issues of her behaviour, but neutrally states that her husband's absence makes it possible for her to walk out. In this account, both her husband and a physician are portrayed as external voices of reason and morality, labelling her walking out as "irresponsible". While admitting that this might be so, $\mathrm{P}$ at the same time asserts the right to independently decide what is good for her (lines 3842). She thus portrays herself as subject to a force, i.e. the fear, that is stronger and more dominating than the social notion of "responsible " or "morally appropriate" behaviour in relation to potential serious illness. 
The GP's response to P's account in line 44, avoids picking up on both the anxiety of hospitals and the issue of moral misconduct. Rather, it transforms P's preceding account to be an explanation for the husband's presence in the consultation. It is hearable as an attempt by the GP to either involve the husband in the interaction or elicit an account for his presence, and therefore is not as such misplaced, but nevertheless tangential to the core components of P's problem as she has just presented it. By phrasing it as a request for confirmation, the GP moreover reverts the interactional relevancies. Instead of responding to the emotional and moral aspects, which P's emotionally loaded problem presentation invites, the GP makes it relevant for $\mathrm{P}$ or her husband to speak again, namely by confirming or disconfirming the GP's interpretation. The work accomplished by the GP's turn in line 44 is captured by the concept of "ancillary questioning", i.e. questions that "[i]n addition to declining affiliative engagement with the experience described by the teller [..] also require that the teller address the agenda raised in the questioner's question" (Heritage 2011, p. 164).

As can be seen from excerpt 1, the GP's project is unsuccessful. The husband produces a confirming answer (line 48), which is potentially prefatory to an explanation of his presence. P however, takes the floor (line 50) and initiates what seems to be a continuation of the husband's answer. As this turn progresses, we can see that its content is not about the husband's presence, but in effect links further back in the conversation, namely to the issues of cancer, and indirectly also the moral issues described above. Looking in detail at lines 50-55, however, we see that $\mathrm{P}$ uses several dramatising expressions like »by god« and »with all my heart« and also the extreme case formulation "no sign whatsoever of a tumour « in lines 53-55 (Pomerantz 1986). Part of the turn, lines 52-53, furthermore, is spoken with a voice on the verge of crying (marked with $\sim$ ). The format of this turn thereby conveys an impression of $\mathrm{P}$ as relating in a highly emotional way to the topic of cancer, and this would seem to counter the impression of the turn as a perfunctory statement. Through this turn design, $\mathrm{P}$ is not just claiming, but is in effect demonstrating, her perception of the sick role as undesirable. This turn, then, implicitly addresses the moral issues of non-cooperation and responsibility that were brought into play previously in the interaction, and that have been analysed above.

Excerpt 1, thus, shows $\mathrm{P}$ as preoccupied with displaying herself as a morally sound person, who shares the social norms pertaining to the sick role, while GP appears to be working to refocus P's displays of anxiety and emotions. 


\section{Disrupted Life or Just Fatigue}

In excerpt 2 below, $\mathrm{P}$ brings up a rather new symptom, namely fatigue. The ensuing analysis aims to point out two separate, but related aspects: Firstly, the rhetorical devices used by $\mathrm{P}$ to portray the severity of her fatigue and at the same time appear credible. Secondly, the different orientations by P and GP to the activity at hand: Whereas GP is narrowly focused on the mapping out of the onset, duration etc. of the symptom, $\mathrm{P}$ is preoccupied with displaying its extraordinary character and pervasive consequences for her life.

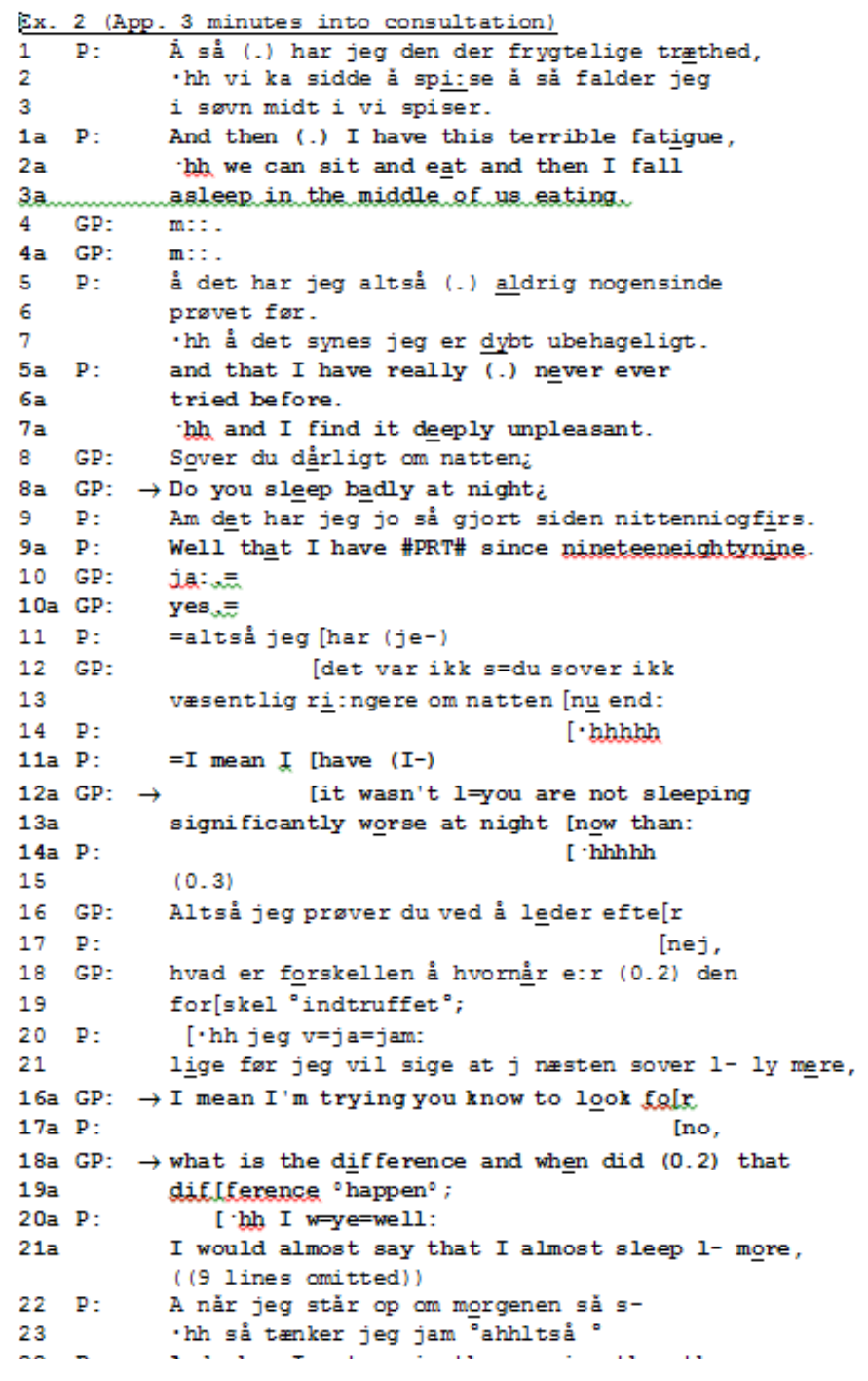




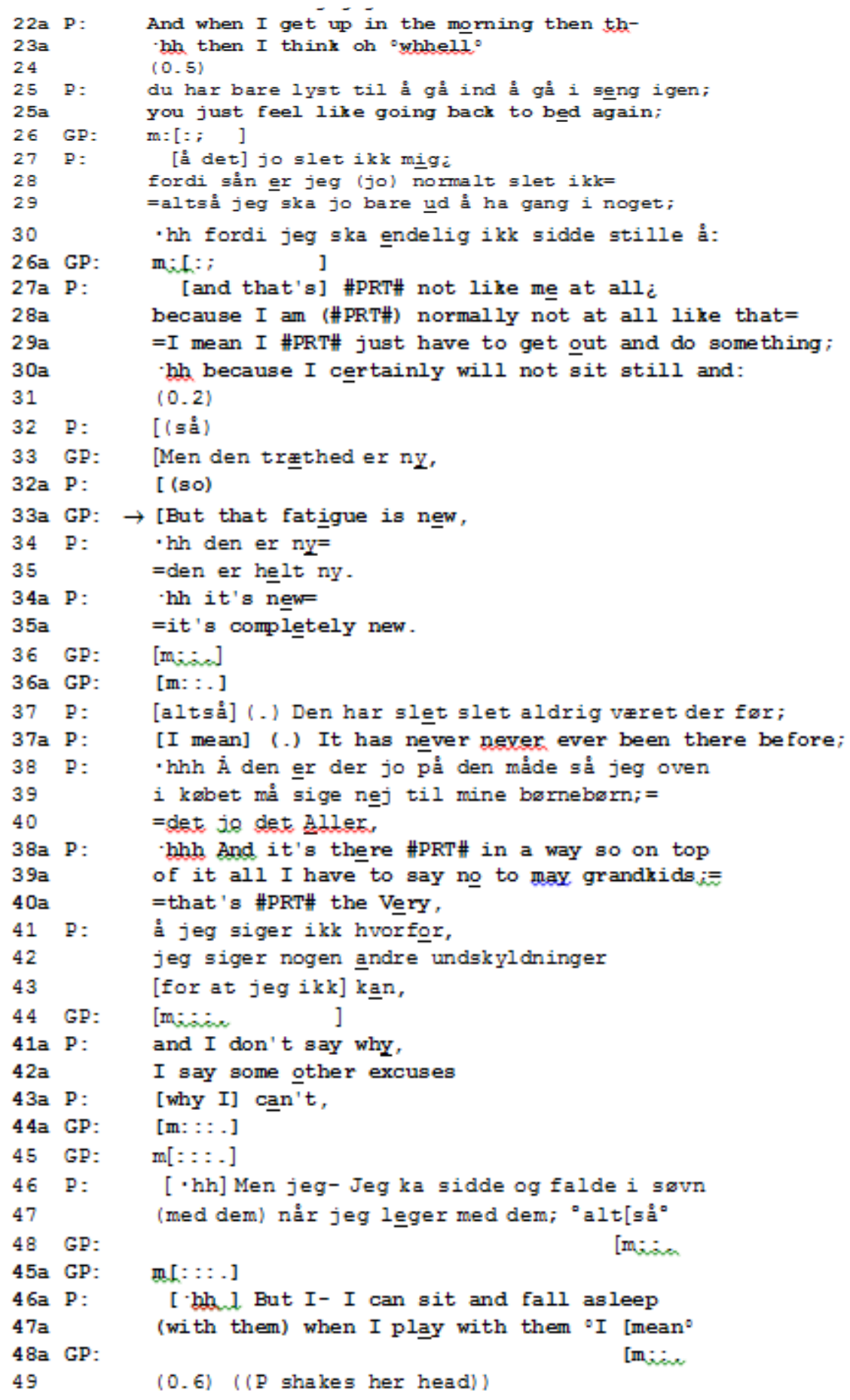




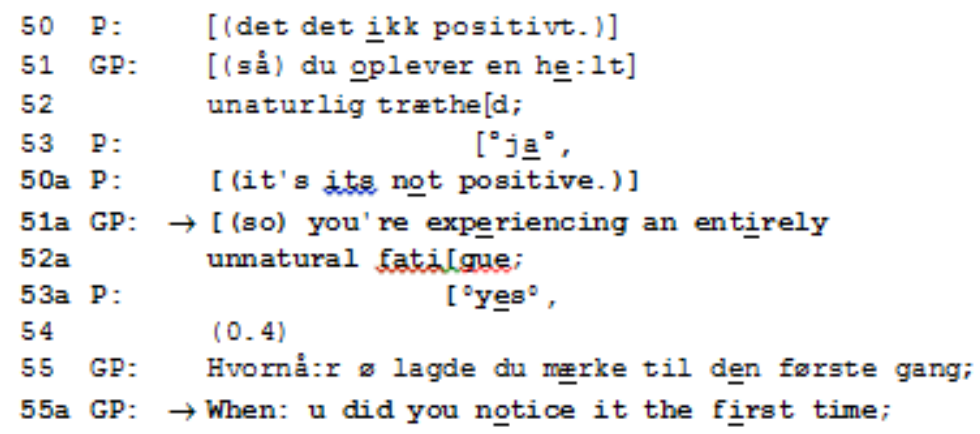

A recurring theme in P's problem presentations is a contrast between a "before" and a "now" and on how the symptoms have disrupted her life and as a consequence her identity. In presenting the fatigue, P constructs the severity of the symptom by describing its present level as markedly worse than ever before (lines 5-6). When describing the pervasive effects of the fatigue on routine, mundane activities (lines 2-3, 22-25), P's perspective is that of the life world (Mishler 1984²). P's rendering of the symptom has a distinct emotional component, displayed for instance in her use of negative descriptors ("terrible", line 1, and "deeply unpleasant", line 7). The GP, however, does not reciprocate the life world or the emotional content of P's symptom presentation, but responds with a neutral, history taking question (line 8), which targets one potential explanation of the fatigue, i.e. lack of sleep. P's answer (line 9) points to the irrelevance of the question, as it dismisses sleeping badly as something out of the ordinary, the implication being that this has been so for the past 21 years. In the ensuing interaction, then, the GP sustains her history-taking agenda, at first by rephrasing the question (lines 1213) and subsequently by accounting for its relevance (lines 16-19). Even though $P$ answers the question (lines 20-21 and in the 9 omitted lines), she does not display an orientation to the interaction as being about history taking. Rather, $\mathrm{P}$ expands her answer, at first by upgrading the severity of the fatigue (lines 22-25), and then through her report of feeling out of character (line 27). This report is substantiated by a characterisation of herself as someone who is usually very active and unable to just sit (lines 28-30).

The self-characterisation is not attended to by the GP, who instead resumes the history-taking agenda, indexing that she still does not have the information she is after (cf. the resuming "But" line 33). P does go along with the factual orientation in GP's question, which she answers affirmatively (lines 34-35 and 37), only to immediately return to the life world perspective. This time she expands her response 
with a complaint about being unable to be with her grandchildren because of the fatigue (lines 38-40, 46-47). Again, $\mathrm{P}$ can be seen to set up a contrast between "before" and "now", this time by portraying her present person as someone who, as a consequence of her symptoms, has become unable to fulfil a grandmother's normal role. The involuntary nature of P's condition is thus emphasised, and by implication, any unspoken assumptions that $\mathrm{P}$ is willingly accepting the sick role and its secondary gains (cf. Parsons 1951) are addressed. The scripting of her life and her identity as disrupted by the symptoms, a "biographical disruption", serves to counter potential inferences of malingering (Horton-Salway 2001, p. 254). The GP in lines 51-52 reformulates P's prior telling to be about "an entirely unnatural fatigue". Although it recognises the extremity of P's state, this formulation also filters away the emotional and identity issues of P's problem and reinstates a clinical line of talk.

Summing up the analytic insights from excerpt 2 above, there is a misalignment between $\mathrm{P}$ and the GP regarding their different orientations to the activity in progress and to what constitutes relevant contributions to the interaction at this very point in the consultation. P's effort to position herself as a morally legitimate person, uses as its vehicle a presentation style that centres on her own emotions and life world experiences in relation to the symptoms. The GP, on the contrary, is focused on the problem and its properties in its own right. Thus, while displaying sensitivity to the problem content of P's symptom presentation, the GP can be said to disattend the emotional content of it. The participants' different orientations are reflected in their turns at talk. The GP frames this part of the interaction according to the conventional pattern for the history-taking phase of a consultation, i.e. as a pursuit of clinically relevant information, typically in the form of repeated question-answer-receipt sequences (Mishler 1984; Frankel 1990). In excerpt 2 , however, $\mathrm{P}$ is repeatedly breaking this "mould" by expanding her answers to the GP's clinically focused questions with emotional and life world issues (Stivers \& Heritage 2001).

\section{Displaying Existential Suffering or Negotiating Future Action}

One consequence of the above described misalignment is a resurfacing of problems and topics already addressed previously in the conversation. In the third, and last, example, the GP has suggested a plan for future action and is pursuing P's accept of it. P, however, does not provide her accept, but returns to the issue already addressed earlier in the conversation, i.e. that of disrupted life. The aim of 
the third analysis is to establish how the participants' different orientations also affect the global course of the interaction and stand in the way of concerted progression. Furthermore, the analysis will address a not yet dealt with, but equally important aspect of P's interactional project, namely to obtain recognition of her suffering from the GP.

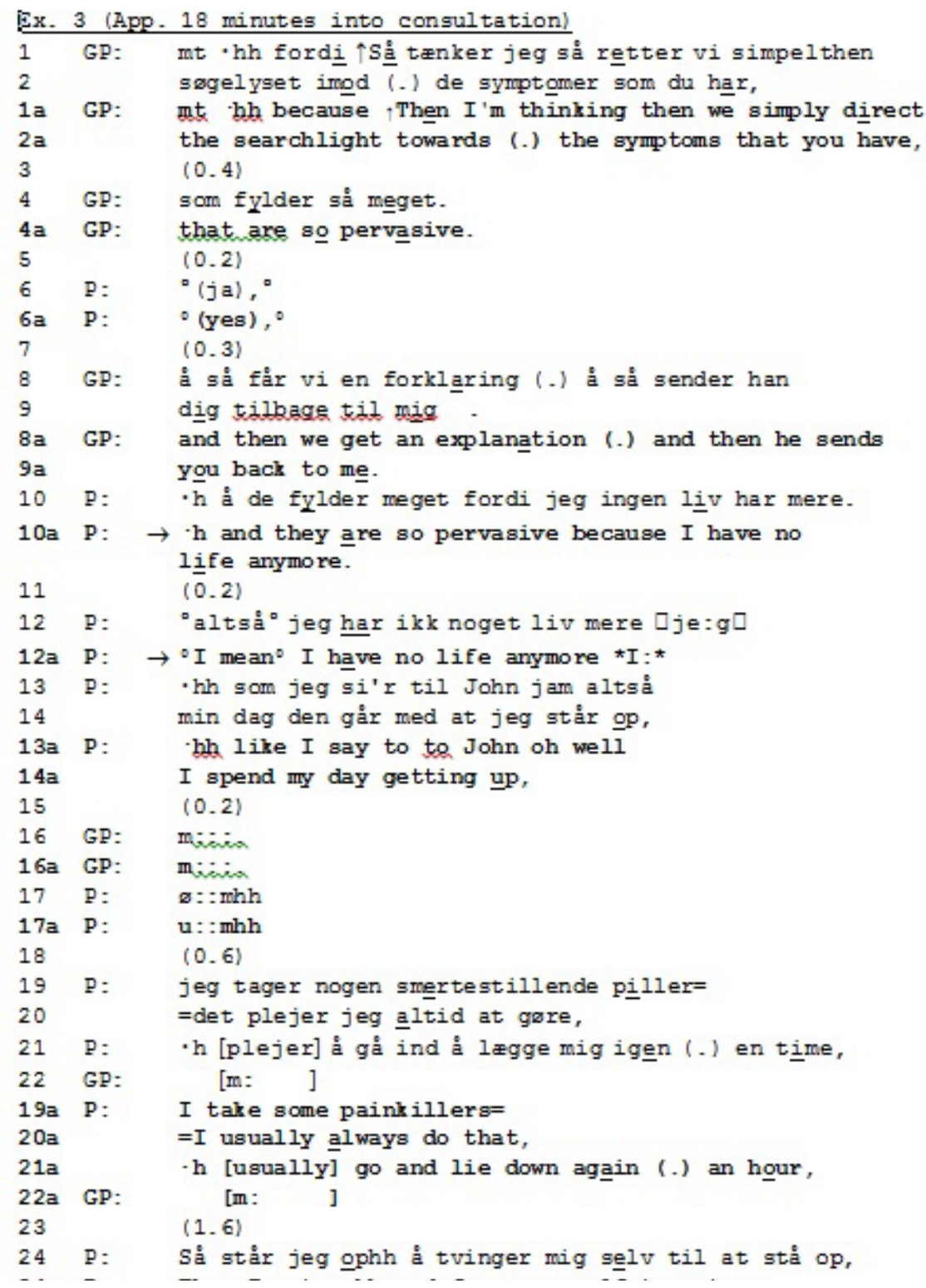




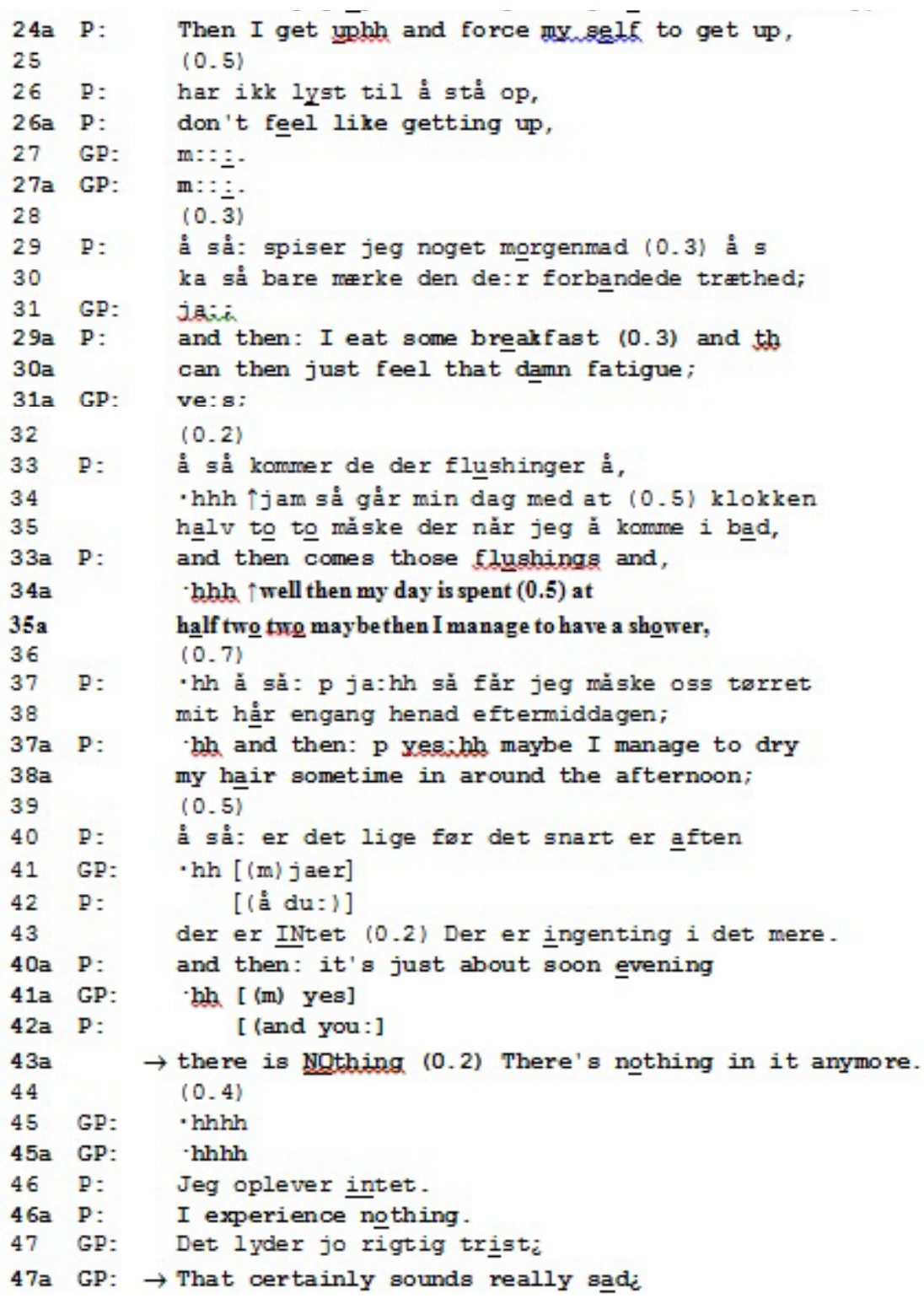

As mentioned in the case history, GP has talked to an endocrinologist prior to the visit, who has agreed to perform all the necessary tests in order to rule out cancer. In the interaction immediately preceding excerpt 3, the GP has introduced this plan. P, however, has not yet agreed, and in lines 1-4 of excerpt 3 we see the GP working to elicit acceptance of the plan by rephrasing the gist of it. P's affirmation (line 6) is weak and ambiguous, and the GP therefore does another pursuit of 
acceptance by further "selling " the plan in lines 8-9. In her response in line 10, $\mathrm{P}$ displays her orientation not towards providing accept, but towards talking about the consequences of her condition for her quality of life. This change of focus is initiated by P's line 10, which is at once dramatically negative and calmly matter of fact. From line 12 to line 40, P unpacks this statement in a narrative detailing of the mundane activities that have come to consume all her energy and fill her days. Part of this detailing is a resumption of an issue already touched upon in excerpt 2, namely the temptation to just stay in bed. Here, however, the point is not to describe the overpowering character of the fatigue, but rather to emphasise how her joie de vivre has been severely reduced as a consequence of her worsened condition. The upshot of the narrative is delivered in line 43. Although it echoes the content of line 10, it makes relevant an entirely different type of response, i.e. one that recognises and reflects the tragic situation that $P$ perceives herself to be in. Such recognition is not immediately forthcoming, and in line $46 \mathrm{P}$ consequently upgrades the negative evaluation of her condition. GP, then, responds with an answer (line 47) that moderately reciprocates the emotional content of P's complaint of essentially having nothing left to live for anymore.

In summary, the GP at this point in the interaction is oriented towards establishing an outcome with regard to future action. P, on the other hand, withholds her accept of the GP's proposal, and instead returns to the topic of disrupted life and existential suffering. This is significant because of its placement in the interaction globally. $\mathrm{P}$ has disclosed her emotional distress on several occasions prior to this, but has received no recognition thereof from the GP. By readdressing the issue, this time around as a topic in its own right, and furthermore at a point when talk about future action projects the imminent closure of the encounter (Robinson 2003), P displays both the all-important status of this subject to her, and her insistence that the GP recognises her suffering.

\section{Discussion}

The analyses have been concerned with central passages from 3 different stages of the consultation, i.e. the initial presentation of the problem and its complex aspects, the mapping out of the symptoms per se, and finally the negotiation of future action. A recurrent feature in the analysed excerpts, and for the case in general, is the misalignment between the patient and the GP. Throughout the con- 
sultation they display different orientations to what kind of activity is in progress at a particular point in time, and consequently to what constitutes a relevant contribution to this activity. The two orientations displayed by the patient and the GP can be characterised as a »troubles-telling « and a »service encounter « orientation respectively. These are distinct activities in that they set up entirely different interactional roles for the participants (Jefferson \& Lee 1981, see above). The service encounter orientation is the default model for physician-patient interaction, at least in acute primary care. As described by Robinson (2003) the clear-cut distribution of roles clearly influences the structure of the interaction and results in the compartmentalisation of the clinical encounter in several, distinct phases, each of which has its own purpose, logic, and role distribution. Thus, the problem presentation phase is a place in the consultation "where patients are systematically given institutional licence to describe their illness in their own terms and in pursuit of their own agenda" (Robinson \& Heritage 2006). In contrast, the activity of taking the history is typically controlled by the physician, and takes the form of question-answer sequences in which both the physician's questions, but also the patient's answers, are oriented towards enabling the diagnosis (Robinson 2003; Boyd \& Heritage 2006). The latter are therefore designed to deliver no more than the relevant information. The physician and the patient conventionally display a common orientation to the treatment decision as the end goal of the encounter, the preceding phases being necessary steps in order to achieve this goal (Robinson 2003). Consequently, there is normally a shared orientation to the progression of the consultation, both locally, i.e. within the individual phases, and globally, i.e. progressing from one phase to the next.

It is, however, exactly this common orientation to the progression of the consultation that is absent in the case under consideration, and as a result, the orientation towards the conventional phases and furthermore the progression towards an outcome is only oriented to by the GP. As a consequence, the GP is consistently framing the talk within a particular format, whereas $\mathrm{P}$ is consistently breaking that format. This happens locally, as in excerpt 2, where P does answer the GP's clinically focused questions, but consistently expands the answers and thus changes the focus to a life world perspective. But it also happens globally, as in excerpt 3 , in which $\mathrm{P}$ cuts off the forward progression of the consultation by reintroducing a topic from an earlier part of the consultation. As a result, the consultation becomes a struggle over the right to define what the relevant activity is at a given point in the interaction, and the participants' different orientations come to obstruct each other and stand in the way of concerted activity. 
Although P's style of communication could be seen as a strategic use of "psychosocial material" for pressuring the GP to some form of somatic intervention (Salmon \& May 1995; Marchant-Haycox and Salmon 1997), we can be quite certain that this is not the outcome $\mathrm{P}$ is striving for here (see the patient's case history above). One very salient project for $\mathrm{P}$, however, is the search for legitimacy and recognition. Although patients' pursuit of medical legitimacy has been described as a fundamental feature of primary care visits (Heritage \& Robinson 2006), in the case of MUS, the issue of legitimacy is intimately linked with the social rights and obligations of being sick, as formulated by Parsons (1951). In the present case, the patient is "inoculating" her presentation of the problem against incredulous receptions of it by constructing an identity of moral and social normality. Her condition, on the other hand, she constructs as an overpowering and uncontrollable threat to that normality. Her suffering, therefore, is hearably not just physical, but also social and, last but not least, existential. The analysed excerpts clearly show P's orientation to making her suffering on these multiple levels visible to and recognised by the GP. P's return to the topic of disrupted life and existential suffering at the point when the consultation is projectably coming to and end, suggests her perception that these issues have not been dealt with or even acknowledged in any satisfactory way. Recognition on multiple levels, that is not just as legitimisation of the incumbency of the sick role, but also of one's person as morally sound and normal would, thus, seem to be a crucial component in the notion of "emotional support", which patients with MUS were found to have an increased need for, compared to other groups of patients (Salmon et al 2005). This furthermore puts the findings by Mik-Meyer and Obling (2012) into perspective. Having researched the self-reported reasoning processes applied by general practitioners in relation to MUS, Mik-Meyer \& Obling find that both the presence of social problems and a "problematic personality « are used by the GPs as criteria for legitimising their classification of patients with medically unexplained complaints as ill (2012). The actual excerpts of an authentic interaction between a MUS patient and a GP exhibited in the present article demonstrate how the presentation of psychosocial problems can be part and parcel of the search for recognition and legitimacy. Together, these results point to the source of the GPs' perception of MUS patients as also shaped by the social and interactional process of negotiating the sick role, which appears to be at the heart of this particular type of medical interaction. Revisiting the Parsonian concept of the sick role, it would, ironically, seem that the endeavour to obtain "conformity within the deviance of illness" (Varul 2010), 
could be part of the explanation as to why some GPs perceive of MUS patients as difficult or as having a problematic personality.

The patient's troubles-talk orientation that has been documented in the analysed interaction poses a dilemma for the GP. On the one hand, taking a service encounter approach enables the GP to avoid the pitfall of psychologising the patient (Åsbring \& Närvänen 2002, Burbaum et al 2010) and instead maintain focus and direction in such a challenging encounter. On the other hand, the eschewal of emotional involvement with the patient also works to deny the patient the recognition and legitimacy that she is so obviously pursuing, thereby causing misalignment and a conversation which, like the one under consideration here, runs in circles. The lack of emotional involvement, thus, is not to be perceived of as an expression of the GP's lack of empathy or ability to communicate empathically, but rather as one way of handling this dilemma. The analysed conversation highlights the inherent difficulties facing even the most empathic and engaged GP when communicating during consultations with MUS patients and the complex nature of this type of conversation.

The results of this article, furthermore, indicate that the interactional resources employed by the GP to implement the service encounter approach, i.e. ancillary questions and orientation towards outcome and progression are all too easily derived from, perhaps even facilitated by, the conventional consultation format, which GPs are trained to master and observe. However, the analytic pinpointing of authentic and recognisable instances of such resources as has been presented above, can therefore serve as a means to raising GPs' awareness of particular interactional behaviours and their communicative consequences, both on their own and on the patients' part.

The analyses and above considerations point to recognition and empathic communication as a key to the potentially problematic medical encounters with MUS patients. However, further microanalytic research is needed in order to explore actual instances of recognition and empathy being used in consultations about MUS. Such research would enable a comparison between the two approaches and their ensuing conversational results. Further research on authentic interactions with MUS patients thus is needed in order to advance our knowledge of how to enhance the management of MUS patients in terms of communication. 


\section{Acknowledgements}

The study was funded by TrygFonden, Aarhus Universitets Forskningsfond and Aarhus University, ARTS. These funding sources had no involvement in the study design, analysis or interpretation of data. We would like to thank the participating doctor and patient, and the anonymous reviewers for their helpful comments.

\section{Notes}

${ }^{1}$ However, the frequently used modal particle "jo" which indicates an expectation that the proposition in which it is embedded is shared knowledge (Heinemann, Lindström \& Steensig 2011) has no verbatim translation in English, and therefore has been rendered as \#PRT\# in the English glossing.

${ }^{2}$ This concept, originally coined by Husserl (1936), is here used in accordance with Mishler (1984), who, building on Habermas' distinction between rational-purposive and symbolic interaction (Habermas 1970) takes »the voice of the life world « to be the patients' lived experiences of the mundane socio-cultural world that they inhabit, their own thoughts, emotions and of course symptoms. In opposition to this is »the voice of medicine«, i.e. the scientific and clinical approach to the symptoms that doctors represent. In his work on doctor-patient communication, a recurrent theme is the way in which the voice of medicine is found to suppress the voice of the life world (Mishler 1984). 


\section{Appendix: Transcription Conventions}

\section{Adapted from Jefferson (2004)}

[ ]

(.)

$=$

:

$><$

$<>$

:

;

$?$

i

in.

And

10Ud

obvious

(such)

( )

$(\mathrm{xxx})$

Overlapping speech

Micro pause (less than 2 tenths of a second)

Pause length (in whole and tenths of seconds)

No break or gap between the utterances that it links

Prolongation of immediately preceding sound

Faster than surrounding talk

Slower than surrounding talk

Falling intonation

Semi-falling intonation

Flat (continuing) intonation

Rising intonation

Semi-rising intonation

Arrows up or down indicate marked shifts in pitch (up or down)

((crying sniff)) Additional comments. e.g. about gestures etc.

$\mathrm{d}(\mathrm{h})$ ead tired(h) $=$ inserted laughter syllables

$\begin{array}{ll}\text { hh } & \text { hh Dot before one or more h's indicate in breath } \\ \text { One or more h's indicate out breath }\end{array}$

\# $\quad$ PRT\#This tag is by no means part of the Jeffersonian conventions, but is used in the English glosses to indicate the presence of the particle "jo" in the Danish utterance (see footnote 1 for the meaning of "jo")| 


\section{References}

Beach, W. A., Dixson, C. N. (2001). Revealing moments: formulating understandings of adverse experiences in a health appraisal interview. Social Science $\mathcal{E}$ Medicine 52: 25-44.

Boyd, E., Heritage, J. (2006). Taking the history: questioning during comprehensive history-taking. In D.W. Maynard \& J. Heritage (Eds.), Communication in Medical Care: Interaction between primary care physicians and patients (pp. 151-184). Cambridge: Cambridge University Press.

Branch, W. T., Malik, T. K. (1993). Using 'Windows of Opportunities' in Brief Interviews to Understand Patients' Concerns. Journal of the American Medical Association 269 (13): 1667-1668.

Burbaum, C., Stresing, A-M., Fritzsche, K., Auer, P., Wirsching, M.. Lucius-Hoene, G.

(2010). Medically unexplained symptoms as a threat to patients' identity? A conversation analysis of patients' reactions to psychosomatic attributions. Patient Education and Counseling 79: 207-217.

Burton, C. (2003). Beyond somatisation: a review of the understanding and treatment of medically unexplained physical symptoms (MUPS). British Journal of General Practice 53: 233-241.

Butow, P. N., Brown, R. F., Gogar S., Tattersall M. H. N.. Dunn, S. M. (2002). Oncologists' reaction to cancer patients' verbal cues. Psycho-Oncology 11: 47-58.

Clements W.M., Haddy, R. Backstrom, D. (1980). Managing the difficult patient. Family Practice 10: 1079-83.

Fink, P., Rosendal, M., Toft, T. (2002). Assessment and Treatment of Functional Disorders in General Practice: The Extended Reattribution and Management Model - An Advanced Educational Program for Nonpsychiatric Doctors. Psychosomatics 43 (2): 93-131.

Frankel, R. (1990). Talking in interviews: A dispreference for patient initiated questions in physician-patient encounters. In G. Psathas (Ed.), Interaction Competence (pp. 231-262). Lanham, MD: University Press of America.

Gallagher, E.B. (1976). Lines of Reconstruction and Extension in the Parsonian Sociology of Illness. Social Science \& Medicine 10: 207-218.

Glenton, C. (2003). Chronic back pain sufferers - striving for the sick role. Social Science $\mathcal{E}$ Medicine 57: 2243-2254.

Goffman, E. (1959). The Presentation of Self in Everyday Life. New York: Anchor Press

Goldberg, D., Gask, L., O'Dowd, T. (1989). The treatment of somatization: Teaching techniques of reattribution. Journal of Psychosomatic Research 33: 689-95

Habermas, J. (1970). Toward a rational society. Boston, MA: Beacon Press.

Hartz, A.J., Noyes, R., Bentler, S.E., Damiano, P.C., Willard, J.C., Momany, E.T. (2000). Unexplained Symptoms in Primary Care: Perspectives of Doctors and Patients. General Hospital Psychiatry 22: 144-152.

Heinemann, T., Lindström, A. Steensig, J. (2011). Addressing epistemic incongruence in question-answer sequences through the use of epistemic adverbs. In T. Stivers, L. Mondada, J. Steensig (Eds.), The Morality of Knowledge in Conversation (pp. 107-130). New York: Cambridge University Press.

Heritage, J. (2011). Territories of knowledge, territories of experience: empathic moments in interaction. In T. Stivers, L., Mondada, and J. Steensig (Eds.), The Morality of Knowledge in Conversation (pp. 159-183). New York: Cambridge University Press. 
Heritage, J. \& Robinson, J. (2006). The Structure of Patients' Presenting Concerns: Physicians' Opening Questions. Health Communication 19 (2): 89-102.

Horton-Salway, M. (2001). Narrative Identities and the Management of Personal Accountability in Talk about ME: A Discursive Psychology Approach to Illness Narrative. Journal of Health and Psychology 6: 247-259.

Husserl, E. (1936). The Crisis of European Sciences and Transcendental Phenomenology. Evanston, IL: Northwestern University Press.

Jefferson, G. (1984). On stepwise transition from talk about a trouble to inappropriately next-positioned matters. In J.M. Atkinson and J. Heritage (Eds.), Structures of Social Action: Studies in Conversation Analysis (pp. 191-221). Cambridge: Cambridge University Press.

Jefferson, G. (2004). Glossary of transcript symbols with an introduction. In G. H. Lerner (Ed.), Conversation Analysis: Studies from the first generation (pp. 13-23). Philadelphia: John Benjamins.

Jefferson, G. \& Lee, J. (1981). The rejection of advice: managing the problematic convergence of a 'troubles-telling' and a 'service encounter'. Journal of Pragmatics 5: 399-422.

Marchant-Haycox, S., Salmon, P. (1997). Patients' and doctors' strategies in consultations with unexplained symptoms: interactions of gynecologists with women presenting menstrual problems. Psychosomatics 38: 440-50.

Mayou, R. (1991). Medically unexplained physical symptoms. British Medical Journal 303: 534-535.

Mik-Meyer, N., Obling, A. R. (2012). The negotiation of the sick role: general practitioners' classification of patients with medically unexplained symptoms. Sociology of Health $\mathcal{E}$ Illness 34 (7): 1025-1038.

Mishler, E.G. (1984). The Discourse of Medicine: Dialectics of Medical Interviews. New Jersey: Ablex Publishing Corporation.

O'Dowd, T.C. (1988). Five years of 'heartsink' patients in general practice. British Medical Journal 297: 528-530.

Parsons, T. (1951). The Social System. New York: Free Press.

Peters, S. Rogers, A., Salmon, P. Gask, L., Dowrick, C., Towey, M. Clifford, R. Morris, R. (2009). What Do Patients Choose to Tell Their Doctors? Qualitative Analysis of Potential Barriers to Reattributing Medically Unexplained Symptoms. Journal of General Internal Medicine 24 (4): 443-449.

Pomerantz, A. (1986). Extreme case formulations: A way of legitimizing claims. Human Studies 9: 219-229.

Reid, S., Whooley, D., Crayford, T., Hotopf, M. (2001). Medically unexplained symptoms: GPs attitudes towards their cause and management. Family Practice 18: 519-523.

Robinson, J. (2003). An Interactional Structure of Medical Activities During Acute Visits and Its Implications for Patients' Participation. Health Communication 15 (1): 27-59.

Robinson, J., Heritage, J. (2006). Physicians' opening questions and patients' satisfaction. Patient Education and Counseling 60: 279-285.

Rosendal, M., Fink, P., Bro, F., Olesen, F. (2005). Somatization, heartsink patients, or functional somatic symptoms? Towards a clinical useful classification in primary health care. Scandinavian Journal of Primary Health Care 23 (1): 3-10.

Ruusuvuori, J. (2007). Managing affect: integration of empathy and problem-solving in health care encounters. Discourse Studies 9 (5): 597-622. 
Salmon, P., May, C.R. (1995). Patients' Influence on Doctors' Behavior: A Case Study of Patient Strategies in Somatization. International Journal of Psychiatry in Medicine 25 (4): 319-329.

Salmon, P., Dowrick, C.F., Ring, A., Humphris, G.M. (2004). Voiced but unheard agendas: qualitative analysis of the psychosocial cues that patients with unexplained symptoms present to general practitioners. British Journal of General Practice 54: 171-176.

Salmon, P., Ring, A., Dowrick, C.F., Humphris, G.M. (2005). What do general practice patients want when they present medically unexplained symptoms and why do their doctors feel pressurized? Journal of Psychosomatic Research 59: 255-262.

Sidnell, J. (2010). Conversation Analysis: An Introduction. Chichester: Wiley-Blackwell.

Stivers, T., Heritage, J. (2001). Breaking the sequential mould: Answering 'more than the question' during comprehensive history taking. Text 21 (1/2): 151-185.

Suchman, A. L., Markakis, K., Beckman, H. B., Frankel, R. (1997). A Model of Empathic Communication in the Medical Interview. Journal of the American Medical Association 277 (8): 678-682.

Szasz, T., Hollender, M.H. (1956) [1987]. The Basic Models of the Doctor-Patient Relationship. In H.D. Schwartz (Ed.), Dominant Issues in Medical Sociology (pp. 74-181). New York: Random House.

Uitterhoeve R., Bensing, J., Dilven E., Donders, R., deMulder P., van Achterberg, T. (2009). Nurse-patient communication in cancer care: does responding to patient's cues predict patient satisfaction with communication. Psycho-Oncology 18: 1060-68.

Varul, M.Z. (2010). Talcott Parsons, the Sick Role and Chronic Illness. Body E Society 16: 72-94.

Ware, N.C (1992). Suffering and the Social Construction of Illness: The Delegitimation of Illness Experience in Chronic Fatigue Syndrome. Medical Anthropology Quarterly 6 (4): 347-361.

Werner, A., Malterud, K. (2003). It is hard work behaving as a credible patient: encounters between women with chronic pain and their doctors. Social Science $\mathcal{E}$ Medicine 57: 14091419.

Werner, A., Isaksen, L.W., Malterud, K. (2004). 'I am not the kind of woman who complains of everything': Illness stories of self and shame in women with chronic pain. Social Science \& Medicine 59: 1035-1045.

Wileman, L., May, C., Chew-Graham, C.A. (2002). Medically unexplained symptoms and the problem of power in the primary care consultation: a qualitative study. Family Practice 19: 178-82.

Zachariae, R., Pedersen C. G., Jensen, A. B., Ehrnrooth E., Rossen P. B., von der Maase, H. (2003). Association of perceived physician communication style with patient satisfaction, distress, cancer-related self-efficacy, and perceived control over the disease. British Journal of Cancer 88: 658-65.

Zimmerman, C., Del Piccolo, L., Bensing, J., Bergvik, S., De Haes, H., Eide, H., Fletcher, I., Goss, C., Heaven, C., Humphris, G., Kim, Y-M., Langewitz, W., Meeuwesen, L., Nuebling, M., Rimondini, M., Salmon, P., van Dulmen, S., Wissow, L., Zandbelt, L. and Finset, A. (2011) Coding patient emotional cues and concerns in medical consultations: The Verona coding definitions of emotional sequences (VR-CoDES). Patient Education and Counseling 82 (2): 141-148. 
Åsbring, P., Närvänen, A. (2002). Women's Experiences of Stigma in Relation to Chronic Fatigue Syndrome and Fibromyalgia. Qualitative Health Research 12 (2): 148-160. 